\title{
Drivetrain design for an ultra light electric vehicle with high efficiency
}

\author{
Isabelle Hofman ${ }^{1,2}$, Peter Sergeant ${ }^{1,2}$ and Alex Van den Bossche ${ }^{2}$ \\ ${ }^{1}$ Dept. Industrial Technology \& Construction, Electrical Energy Research Group, Ghent University, Gent, Belgium \\ ${ }^{2}$ Dept. Electrical Energy, Systems \& Automation, Electrical Energy Laboratory, Ghent University, Gent, Belgium \\ Isabelle.Hofman@Ugent.be
}

\begin{abstract}
The complete drivetrain for a single person ultra light electric vehicle (EV) is optimized towards a minimal total weight and a maximal average efficiency for different driving cycles. The EV is named ELBEV, which is an acronym for Ecologic Low Budget Electric Vehicle. The single person ultra light EV is a tricycle, with two driven and steering front wheels and one rear wheel. The drivetrain of each front wheel consists of an outer rotor permanent magnet synchronous motor (PMSM), a single-stage gearbox and the power electronics with converter and controller print. The drivetrain is optimized for the New European Driving Cycle, the New York City Cycle and the Federal Test Procedure. For the optimization of the drivetrain analytical models are used to calculate the losses and the efficiency. The optimized parameters of the motor are: the number of pole pairs, the number of stator slots and the outer rotor radius of the motor. Furthermore, an analytical model for the single-stage gearbox is implemented for different gear ratios (GRs). The optimized parameters for the gearbox are: the number of teeth and the module of each gear combination and the total mass of the gearbox for each GR. The analytical models are fast, and useful for designing a good PMSM in combination with a single-stage gearbox. The optimization of the complete drivetrain is always a compromise between total average efficiency over the drive cycle and the total mass of the drivetrain.
\end{abstract}

Keywords: Integrated design, Drivetrain, Ultra light electric vehicle

\section{Introduction}

The main reasons why people choose for an electric vehicle (EV) is because they want to reduce the dependence on foreign oil and they want to mitigate the climate change. The major problem of commercial EVs today is the high cost of the vehicle. This is due to the large amount of batteries and because of that the high weight of the vehicle, but also because of the high cost of the battery technology. Therefore, we want to design an ultra light electric vehicle named the ELBEV, acronym for Ecologic Low Budget Electric Vehicle. The goal is to have a transportation method with less energy consumption than a commercial EV but yet much faster, more comfortable and safer than a bike.

\subsection{Ecologic Low Budget Electric Vehi- cle}

The ELBEV (Fig.1) is a one person EV with batteries, mainly for commuting purposes in the city and in the suburbs. The vehicle is controlled by the driver via two contactless handles [1]: a gas and a brake handle. The low cost car has three wheels, two driven and steering front wheels and one rear wheel. The maximum speed of the car is $80 \mathrm{~km} / \mathrm{h}$ and the range is about $100 \mathrm{~km}$. The total curb weight (batteries included) is about 100 $\mathrm{kg}$. The battery pack consists of Lithium Polymer batteries with a high energy to weight ratio: $20 \mathrm{Ah}, 96 \mathrm{~V}$ and $11 \mathrm{~kg}$. The dimensions of the car are: a total length of $2200 \mathrm{~mm}$, a total width of $1200 \mathrm{~mm}$ and a total height of $1300 \mathrm{~mm}$. 


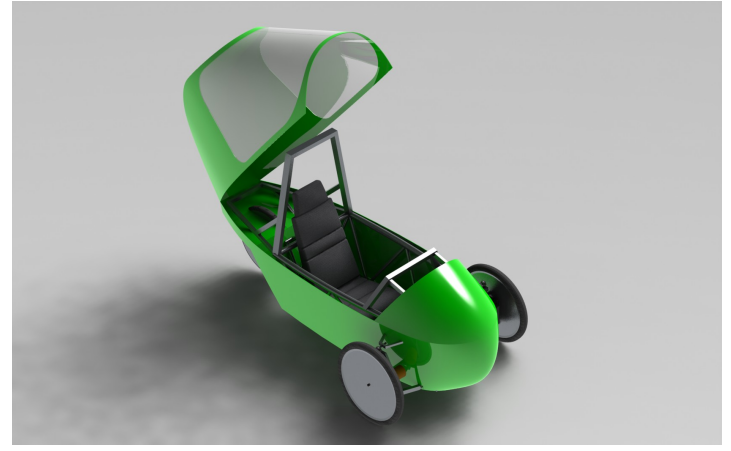

Figure 1: Ecologic Low Budget Electric Vehicle.

\subsection{Drivetrain of each front wheel of the ELBEV}

Each front wheel of the ELBEV is driven by a motor with gearbox and power electronics. The block diagram of the drivetrain for ELBEV is shown in Fig. 2.

The battery (1) provides the power stage of each brushless DC (BLDC) motor with current. The power stage (2) is connected to the three stator coils of the BLDC motor (3). Each of the stator coils is powered by a half bridge, two of them contain a current sensor (4) to measure two phase currents $\left(I_{a}\right.$ and $\left.I_{b}\right)$ flowing through the motor. The two phase currents are measured by the control print (5). The third phase current is equal to the negative sum of $I_{a}$ and $I_{b}$, this is done by electronics on the control print [2]. The control print is fed by a flyback converter on the power stage. With the hall sensors (6), mounted on the BLDC motor, the exact rotor position is known. This signal is also coupled with the control print. The signal is then fed to the power stage to switch on the correct transistors to drive the motor. The drive signal (7) and the brake signal (8) from the handles are fed to the control print. An enable button (9) is also mounted, to switch on the electronics. With the torque direction button (10) the driving direction of the vehicle can be reversed. The BLDC motor is coupled with a single stage gearbox (11) in order to reduce the speed and increase the torque of the motor on the front wheel (12).

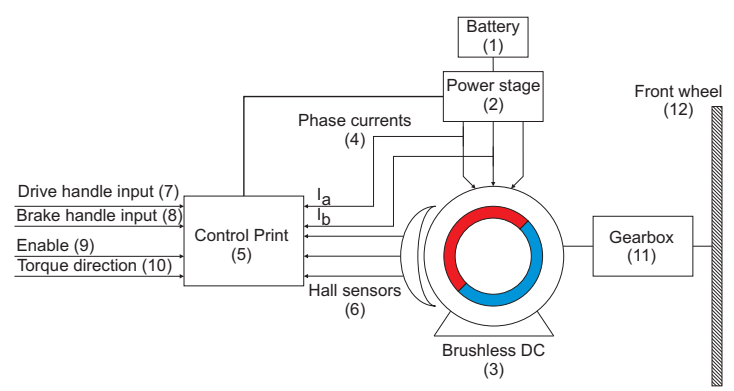

Figure 2: Drivetrain for each front wheel of the ELBEV.

\section{Integrated design}

In the past, the power electronics and controller have been developed and tested. A gearbox has been designed, built and tested together with a commercial outer rotor permanent magnet synchronous motor (PMSM). A new optimized design for this motor is currently implemented in combination with an improved single-stage gearbox. The objective function in the optimization process is shown in Fig. 3.

$$
G R, N_{\mathrm{p}}, N_{\mathrm{S}} \text { and } r_{\text {rotor }}
$$

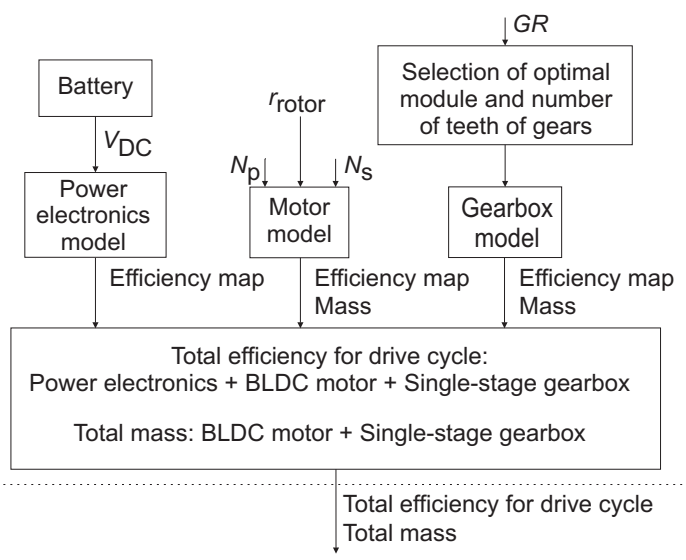

Figure 3: Objective function that is executed for gear ratios $=\frac{1}{2}-\frac{1}{7}, N_{p}=3-8, N_{s}=9-18$ and $r_{\text {rotor }}=$ $0.04-0.1 \mathrm{~m}$.

The optimized parameters for the new outer rotor PMSM are the number of pole pairs $\left(N_{p}\right)$, the number of stator slots $\left(N_{s}\right)$ and the outer rotor radius of the motor $\left(r_{\text {rotor }}\right)$. Therefore we use an analytical model to calculate the losses and the efficiency of the PMSM. Moreover, the total active mass of the motor is calculated.

For the single-stage gearbox an analytical model is implemented for different gear ratios (GRs) in order to have a minimal weight for each GR. The GRs that were investigated are $\frac{1}{2}$ to $\frac{1}{7}$. Each of the motor and wheel gear combinations are able to transfer the required peak torque on the wheel. Fig. 4 shows the mass for several possible gears (motor and wheel gear combinations for the single-stage gearbox) for a GR of $\frac{1}{2}$. Each of the markers defines a combination of motor and wheel gears with a different module and/or different teeth numbers. From the figure, it is clear that the combination of 40 teeth at motor side and 80 teeth at wheel side with module 1 , gives the lowest total mass for the different gear combinations. This approach was used for each GR. It is a sub optimization shown in the objective function of Fig. 3.

The PMSM and gearbox are optimized for the New European Driving Cycle (NEDC), the New 


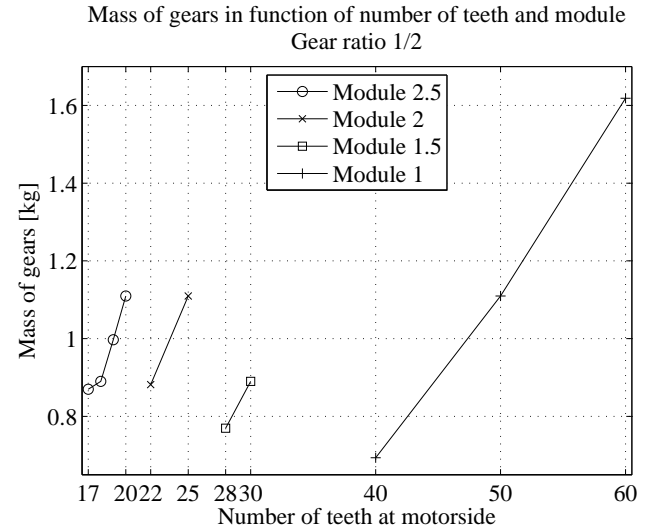

Figure 4: Weight of several gears for a single-stage gearbox with gear ratio $\frac{1}{2}$. All shown combinations are able to transfer the required peak torque on the wheel, so that the figure makes it possible to select the gear with the lowest mass. Note that, as even numbers of teeth and integer multiples of teeth are not common practice in gears, the optimal combination 40-80 could be slightly modified to e.g. 41-81.

York City Cycle (NYCC) and the Federal Test Procedure (FTP) [4], [5]. The NEDC is shown in Fig. 5, but due to the maximum speed of 20 $\mathrm{m} / \mathrm{s}$ of the ELBEV, the NEDC is cut off at that specific speed. Fig. 6 shows the NYCC and Fig. 7 the FTP (dashed line is the maximum speed of the ELBEV).

The goals are a minimization of total weight and a maximization of the total average efficiency of the drivetrain for the different driving cycles, consisting of the power electronics, the PMSM and the gearbox.

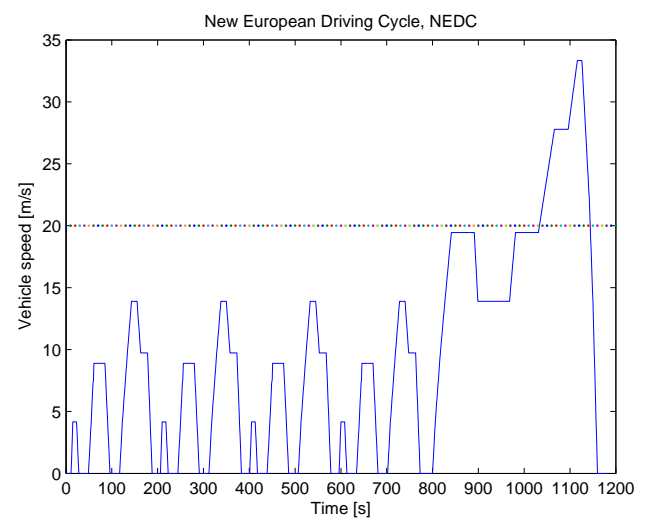

Figure 5: New European Driving Cycle, the dashed line is the maximum speed of the ultra light electric vehicle. Important parameters of the NEDC: average speed: $33.6 \mathrm{~km} / \mathrm{h}$, maximum speed: $120 \mathrm{~km} / \mathrm{h}$, total distance: $11.017 \mathrm{~km}$ and duration: $1180 \mathrm{~s}$ [3].

Fig. 8 shows the calculated efficiency map of a

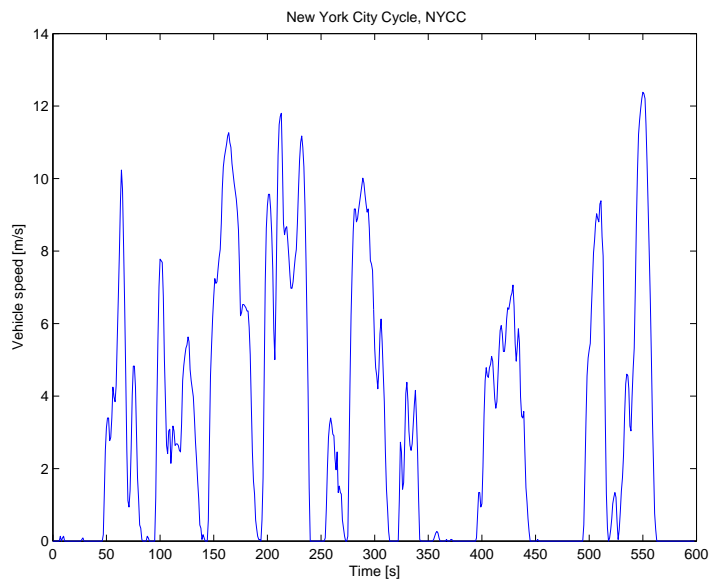

Figure 6: New York City Cycle. Important parameters of the NYCC: average speed: $11.5 \mathrm{~km} / \mathrm{h}$, maximum speed: $44.45 \mathrm{~km} / \mathrm{h}$, total distance: $1.903 \mathrm{~km}$ and duration: 598 s.

PMSM with $N_{p}=7, N_{s}=12$ and $r_{\text {rotor }}=0.04$ $\mathrm{m}$. The average efficiency is $93.63 \%$ in a speed range of $0.5 N_{\text {nom }}-N_{\text {nom }}$ and in a torque range of $0.5 T_{\text {nom }}-T_{\text {nom }}$. The maximum efficiency is $94.34 \%$. Note that the crosses in the figure show the working points over the NEDC. In Fig. 9 and Fig. 10 the same calculated efficiency map of the motor as in Fig. 8 is shown, but now with the working points over the NYCC and the FTP (see Fig. 9 and Fig. 10).

\section{Results}

The objective function of Fig. 3 is executed for several GRs and for a range of the motor parameters $N_{s}, N_{p}$ and $r_{\text {rotor }}$. For each combination of input parameters, the total mass and average efficiency of the drivetrain are computed for the different driving cycles. The total mass of the drivetrain (motor + single-stage gearbox) is the same for each driving cycle, and is shown in Fig. 11. For each driving cycle (NEDC, NYCC and FTP) the average efficiency is shown in Fig 12, Fig 13 and Fig. 14.

Table 1: Results total drivetrain with single-stage gearbox for three driving cycles for gear ratio $\frac{1}{3}$

\begin{tabular}{lrrr}
\multicolumn{4}{c}{$G R: 1 / 3, r_{\text {rotor }}: 0.055 \mathrm{~m}, N_{p}: 7, N_{s}: 12$} \\
\hline Property & NEDC & NYCC & FTP \\
\hline Av. total eff. & $85.72 \%$ & $71.15 \%$ & $85.37 \%$ \\
Driving range & $112.98 \mathrm{~km}$ & $325.77 \mathrm{~km}$ & $125.61 \mathrm{~km}$ \\
Total mass & \multicolumn{3}{c}{$8.9912 \mathrm{~kg}$} \\
\hline
\end{tabular}

From all these solutions, the following trends are observed: For a drivetrain (motor + power electronics + gearbox) with $N_{p}=7, N_{s}=12$, 


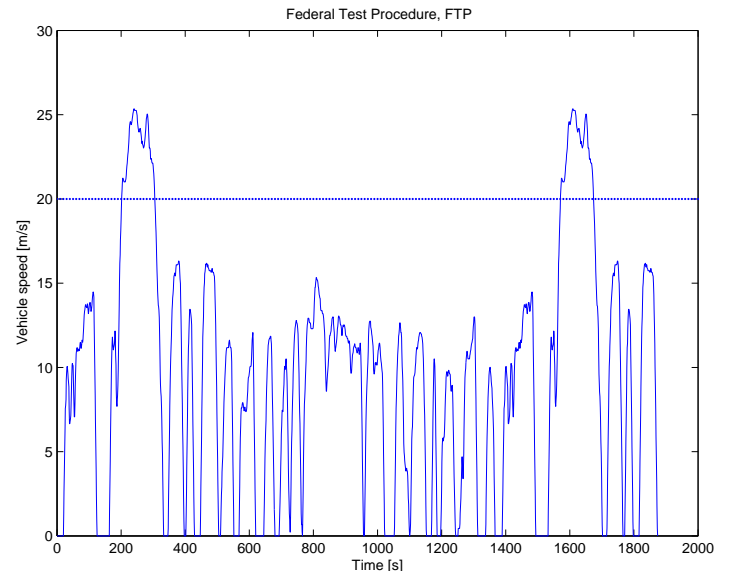

Figure 7: Federal Test Procedure, the dashed line is the maximum speed of the ultra light electric vehicle. Important parameters of the FTP: average speed: 34.2 $\mathrm{km} / \mathrm{h}$, maximum speed: $91.09 \mathrm{~km} / \mathrm{h}$, total distance: $17.787 \mathrm{~km}$ and duration: $1874 \mathrm{~s}$.

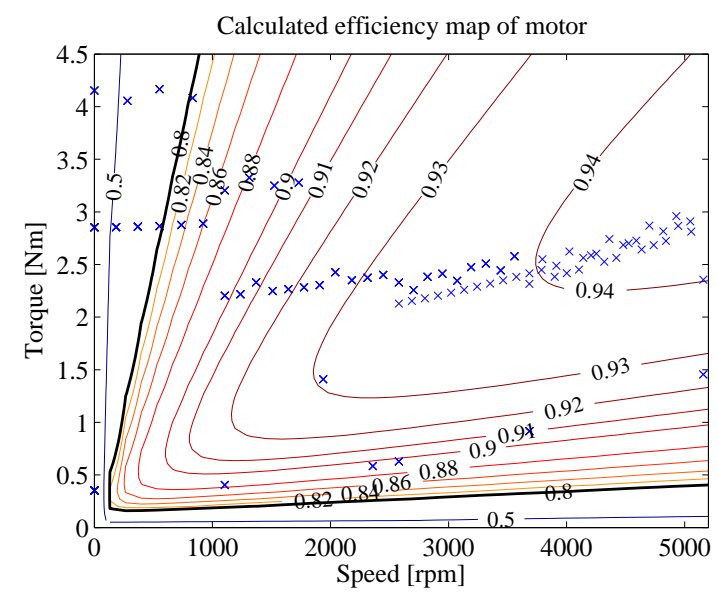

Figure 8: Calculated efficiency map of the motor $\left(G R=\frac{1}{7}, N_{p}=7, N_{s}=12\right.$ and $\left.r_{\text {rotor }}=0.04 \mathrm{~m}\right)$. The crosses show the working points over the NEDC.

Table 2: Results total drivetrain with single-stage gearbox for three driving cycles for gear ratio $\frac{1}{7}$

$$
G R: 1 / 7, r_{\text {rotor }}: 0.04 \mathrm{~m}, N_{p}: 7, N_{s}: 12
$$

\begin{tabular}{lrrr}
\hline Property & NEDC & NYCC & FTP \\
\hline Av. total eff. & $85.56 \%$ & $76.18 \%$ & $85.57 \%$ \\
Driving range & $112.77 \mathrm{~km}$ & $348.80 \mathrm{~km}$ & $125.91 \mathrm{~km}$ \\
Total mass & \multicolumn{3}{c}{$12.5820 \mathrm{~kg}$} \\
\hline
\end{tabular}

$r_{\text {rotor }}=0.055 \mathrm{~m}$ and a GR of $\frac{1}{3}$ the total mass of the drivetrain is $8.99 \mathrm{~kg}$ (mass 1 gearbox $=2.33$ $\mathrm{kg}$, mass 1 motor $=2.16 \mathrm{~kg}$ ), but the average efficiency and thus the driving range depend on the drive cycle, see Table 1 . When comparing this result (Table 1) with Table 2, the conclusion

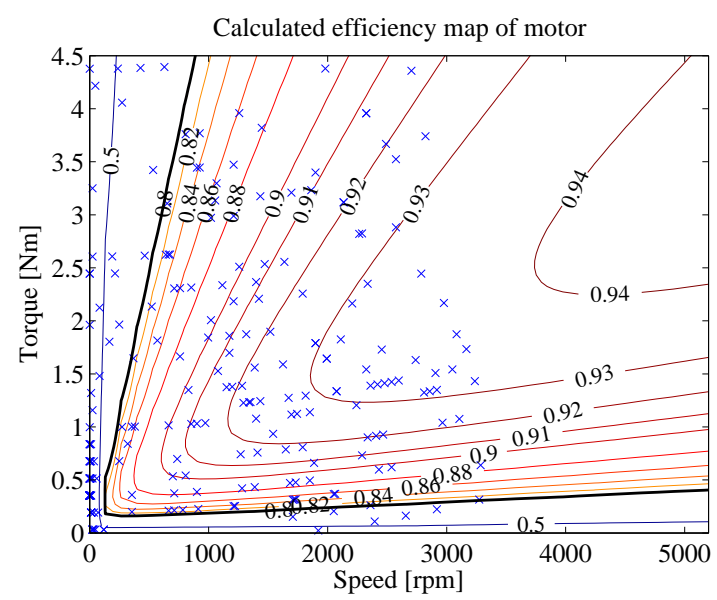

Figure 9: Calculated efficiency map of the motor $\left(G R=\frac{1}{7}, N_{p}=7, N_{s}=12\right.$ and $\left.r_{\text {rotor }}=0.04 \mathrm{~m}\right)$. The crosses show the working points over the NYCC.

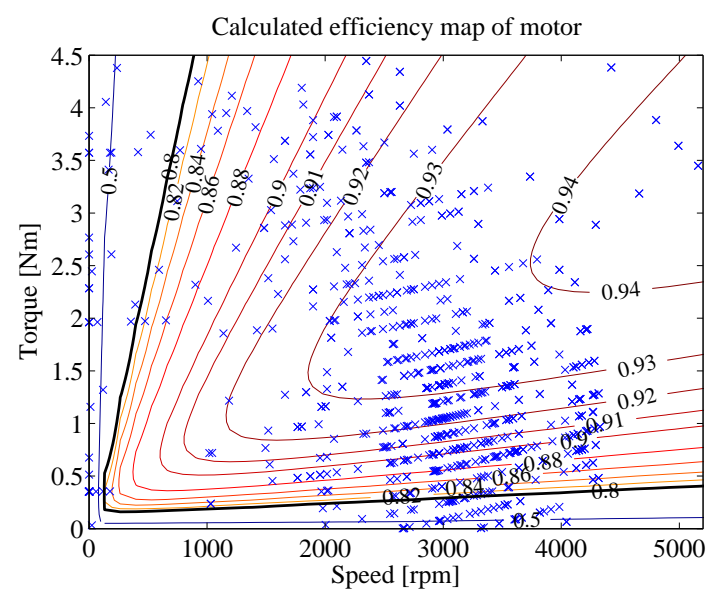

Figure 10: Calculated efficiency map of the motor $\left(G R=\frac{1}{7}, N_{p}=7, N_{s}=12\right.$ and $\left.r_{\text {rotor }}=0.04 \mathrm{~m}\right)$. The crosses show the working points over the FTP.

is that for almost the same average efficiency over the NEDC $(85 \%)$ the total mass of the complete drivetrain is $3.59 \mathrm{~kg}$ higher when using a drivetrain with $N_{p}=7, N_{s}=12, r_{\text {rotor }}=0.04$ $\mathrm{m}$ and a GR of $\frac{1}{7}$. The total mass of the drivetrain in Table 2 is $12.58 \mathrm{~kg}$ (mass 1 gearbox $=5.31 \mathrm{~kg}$, mass 1 motor $=0.98 \mathrm{~kg}$ ), and again the average efficiency and thus the driving range depend on the drive cycle.

\section{Conclusions}

By optimization of the complete drivetrain over the different driving cycles it is possible to choose a good combination of motor and single-stage gearbox in order to have high average efficiency and a minimal weight. 


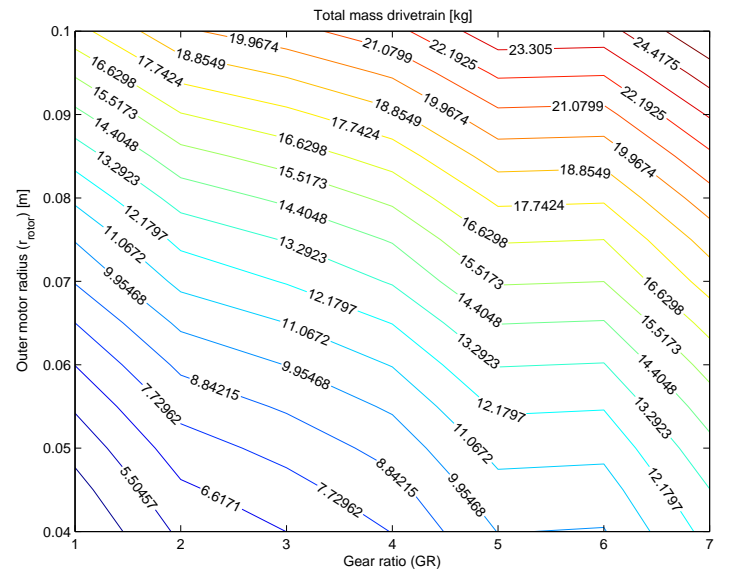

Figure 11: Total mass of drivetrain with single-stage gearbox for each drive cycle.

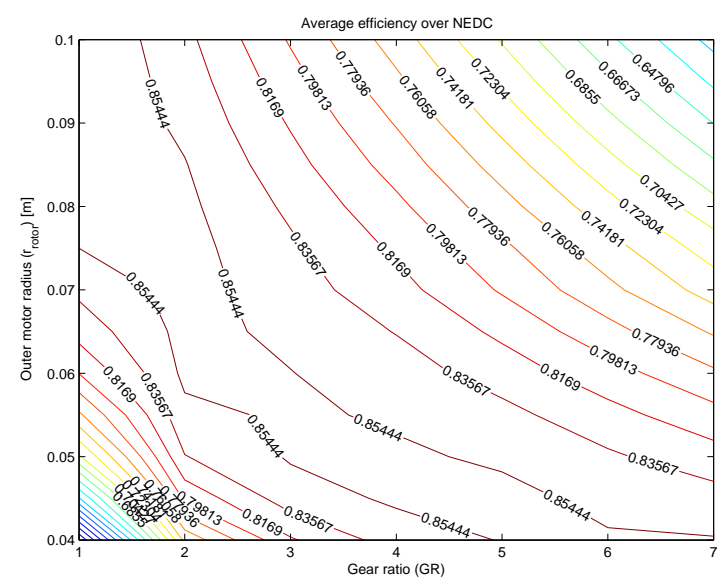

Figure 12: Average efficiency over the NEDC. The ridge $(85.44 \%)$ shows the combinations of GR and outer motor radius that yield the highest average efficiency. For a low GR of $\frac{1}{2}$, the highest average efficiency is obtained with a motor of double radius compared to a high GR of $\frac{1}{7}$.

Optimization for different driving cycles will result in an optimal combination of motor and gearbox for that driving cycle.

\section{References}

[1] A. Van den Bossche and P. Sergeant, "Eddy current based, contactless position transducer for a gas handle," IEEE, Proceedings of the 2010 Vehicle Power and Propulsion Conference (VPPC 2010), Published: 2010.

[2] A. Van den Bossche, DV. Bozalakov, T. Vyncke and VC. Valchev, "Programmable Logic Device Based Brushless DC Motor Control," IEEE, Proceedings of the 201114th European conference on Power Elec-

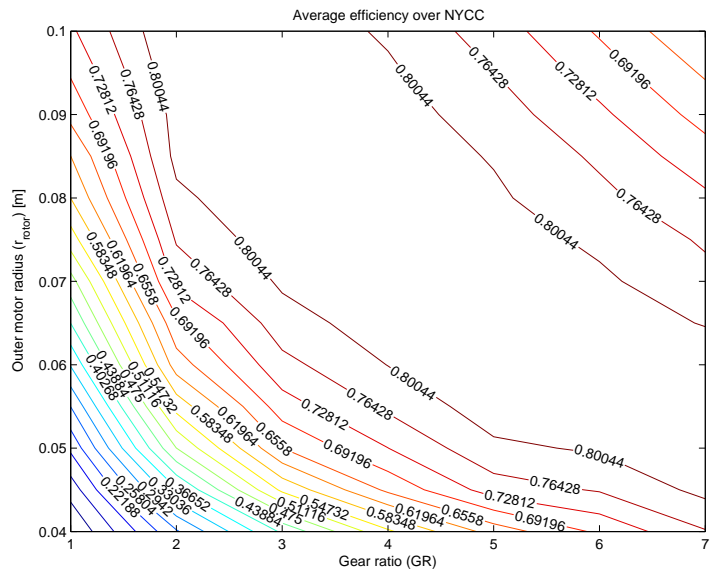

Figure 13: Average efficiency over the NYCC. The ridge $(80.04 \%)$ shows the combinations of GR and outer motor radius that yield the highest average efficiency.

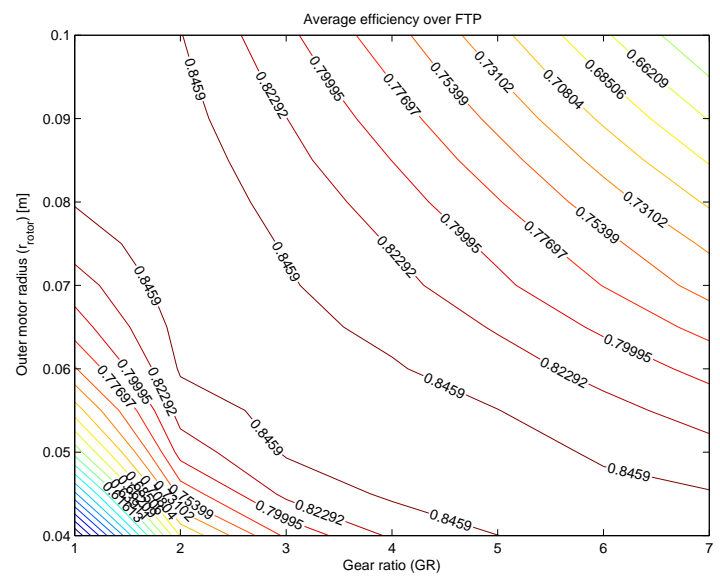

Figure 14: Average efficiency over the FTP. The ridge $(84.59 \%)$ shows the combinations of GR and outer motor radius that yield the highest average efficiency. For a low GR of $\frac{1}{2}$, the highest average efficiency is obtained with a motor of double radius compared to a high GR of $\frac{1}{7}$.

tronics and Applications (EPE 2011), Published: 2011.

[3] Regulation No 101 of the Economic Commission for Europe of the United Nations (UN/ECE) Uniform provisions concerning the approval of passenger cars powered by an internal combustion engine only, or powered by a hybrid electric power train with regard to the measurement of the emission of carbon dioxide and fuel consumption and/or the measurement of electric energy consumption and electric range, and of categories M 1 and N 1 vehicles powered by an electric power train only with regard to the measurement of electric energy consumption and electric range, Official Journal L 138 , 26/05/2012 P. 00010077. 
[4] T.J. Barlow, S. Latham, I.S. McCrae, P.G. Boulter, "PPR354," in A reference book of driving cycles for use in the measurement of road vehicle emissions, TRL, 2009.

[5] W. Courtois. (2013, Aug. 20). Dynamometer Drive Schedules [Online]. Available: http://www.epa.gov/dynamometer.htm

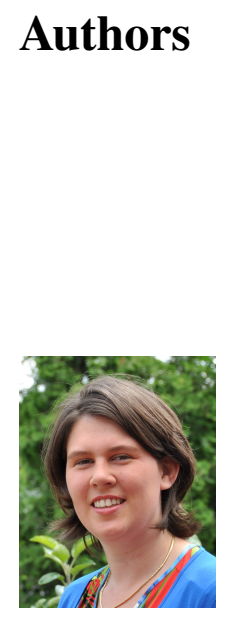

Isabelle Hofman received the master degree in electromechanical engineering in 2010 from the University College of Ghent, Belgium. In 2010, she became a Ph.D. researcher in a project entitled Ecologic Low Budget Electric vehicle at the University College of Ghent. Her research is in the field of electric drives for light electric vehicles.

Peter Sergeant received the M.Sc. degree in electromechanical engineering in 2001, and the Ph.D. degree in engineering sciences in 2006, both from Ghent University, Ghent, Belgium. In 2001, he became a researcher at the Electrical Energy Laboratory of Ghent University. He became a postdoctoral researcher at Ghent University in 2006 (postdoctoral fellow of the Research Foundation - Flanders) and at Ghent University College in 2008. Since 2012, he is associate professor at Ghent University and Ghent University College. His current research interests include numerical methods in combination with optimization techniques to design nonlinear electromagnetic systems, in particular, electrical machines for sustainable

energy applications.

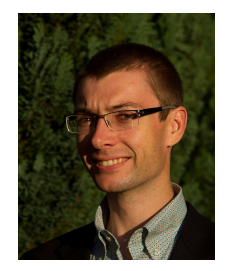

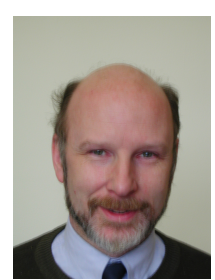

Alex P. M. Van den Bossche received the M.Sc. and the Ph.D. degrees in electromechanical engineering from Ghent University Belgium, in 1980 and 1990 respectively. He has worked there at the Electrical Energy Laboratory (EELAB). Since 1993, he is professor at the same university in the same field. His research is in the field of electrical drives, power electronics on various converter types and passive components and magnetic materials. He is also interested in renewable energy conversion. He is an author of the book Inductors and transformers for power electronics. He was a starter of the spinoff companies Inverto n.v. (1990) and recently Alenco n.v. (2009). $\mathrm{He}$ is an IEEE member since 2000 and a senior member of IEEE since 2003. 